\title{
JANEX-1, a JAK3 inhibitor, ameliorates tumor necrosis factor- $\alpha$-induced expression of cell adhesion molecules and improves myocardial vascular permeability in endotoxemic mice
}

\author{
JUNG EUN LEE ${ }^{1}$, AE SIN LEE ${ }^{1}$, DUK HOON KIM ${ }^{1}$, YU JIN JUNG ${ }^{1}$, SIK LEE ${ }^{1}$, BYUNG-HYUN PARK ${ }^{2}$, \\ SUN HWA LEE ${ }^{1}$, SUNG KWANG PARK ${ }^{1}$, WON KIM ${ }^{1}$ and KYUNG PYO KANG ${ }^{1}$ \\ Departments of ${ }^{1}$ Internal Medicine, Research Institute of Clinical Medicine and Diabetes \\ Research Center, and ${ }^{2}$ Biochemistry and Diabetes Research Center, Chonbuk National \\ University Medical School, Deokjin-gu, Jeonju-si 561-712, Republic of Korea
}

Received December 19, 2011; Accepted February 1, 2012

DOI: $10.3892 / \mathrm{ijmm} .2012 .920$

\begin{abstract}
Vascular endothelial cells play an important role in leukocyte trafficking during the inflammatory process. Proinflammatory cytokines activate the expression of cell adhesion molecules in endothelial cells. Janus kinase (JAK) and signal transducer and activator of transcription (STAT) are important intracellular cytokine signaling molecules that are involved in immune responses. The purpose of this study was to investigate the effect of JAK3 inhibition on the expression of tumor necrosis factor (TNF)- $\alpha$-induced cell adhesion molecules in vascular endothelial cells and to evaluate the therapeutic potential of JAK3 for myocardial vascular permeability in endotoxemic mice. A JAK3 inhibitor, JANEX-1, decreased the TNF- $\alpha$-induced expression of intercellular adhesion molecule (ICAM)-1, VCAM (vascular cell adhesion molecule)-1 and fractalkine in human umbilical vein endothelial cells (HUVECs). The downregulation of the expression of these cell adhesion molecules by JANEX-1 was mediated via suppression of STAT3 phosphorylation and nuclear factor- $\kappa \mathrm{B}$ $(\mathrm{NF}-\kappa \mathrm{B})$ activation. In endotoxemic mice, pretreatment with JANEX-1 prevented not only an increase in the cardiac ICAM-1 expression by LPS in the arteriolar and capillary
\end{abstract}

Correspondence to: Dr Kyung Pyo Kang, Department of Internal Medicine, Chonbuk National University Medical School, 20 Geonjiro, Deokjin-gu, Jeonju-si 561-712, Republic of Korea

E-mail:kpkang@chonbuk.ac.kr

Abbreviations: HUVECs, human umbilical vein endothelial cells; ICAM-1, intercellular adhesion molecule-1; IFN- $\gamma$, interferon- $\gamma$; IL-1 $\beta$, interleukin-1 $\beta$; JAK, Janus kinase; LPS, lipopolysaccharide; NF- $\kappa \mathrm{B}$, nuclear factor- $\kappa \mathrm{B}$; STAT, signal transducer and activator of transcription; TNF- $\alpha$, tumor necrosis factor- $\alpha$; VCAM-1, vascular cell adhesion molecule-1

Key words: cell adhesion molecules, endotoxemia, JAK/STAT pathway, $\mathrm{NF}-\kappa \mathrm{B}$, vascular permeability endothelial cells, but also myocardial vascular leakage. These results suggest that inhibition of the JAK/STAT pathway by JANEX-1 ameliorates the expression of TNF- $\alpha$-induced cell adhesion molecules in HUVECs and improves myocardial vascular permeability.

\section{Introduction}

Sepsis is a systemic inflammatory response to severe infection and is characterized by multi-organ dysfunction and hemodynamic compromise (1). A pathophysiological feature of sepsis is the production of proinflammatory mediators, such as cellular adhesion molecules, cytokines, and chemokines by vascular endothelial and inflammatory cells (2). Among these cells, the vascular endothelial cells play important roles both in forming a structural barrier between circulating blood and the underlying tissue and in generating vasoactive mediators, such as nitric oxide, prostacyclin, endothelin, and platelet-activating factor in response to physiological or pathological conditions (3). Infiltration of leukocytes from the circulatory system to the inflammatory site requires the expression of adhesion molecules and multiple signaling cascades in endothelial cells $(3,4)$. Therefore, therapeutic strategies focused on the regulation of the interaction between circulating leukocytes and endothelial cells might be a plausible approach to treat sepsis-induced organ dysfunction.

The first step in the initiation of inflammatory cascades is the binding of a cytokine to its corresponding receptor, leading to a change in gene expression. Among these signaling pathways, the Janus kinase (JAK)/signal transducer and activator of transcription (STAT) pathway participates in the signaling of many cytokines and is involved in stress-responsive gene expression, immune response, myocardial ischemic preconditioning and the remodeling of post-myocardial infarction (5-8). In response to proinflammatory stimuli in endotoxemia, the nuclear factor- $\kappa \mathrm{B}(\mathrm{NF}-\kappa \mathrm{B})$ signaling pathway is activated and coordinates the inflammatory cascade (9). Interactions between NF- $\mathrm{NB}$ and STAT3 may play an important role in inflammation-mediated tumor progression and may control the production of proinflammatory cytokines and chemokines 
in immune cells $(10,11)$. Therefore, the modulation of the $\mathrm{NF}-\kappa \mathrm{B}$ and JAK/STAT signaling pathways may help reduce endotoxemia-induced myocardial dysfunction.

Within the JAK family, JAK3, in contrast to other JAK family members, is preferentially expressed in the lymphoid or myeloid cell lineages (12). JAK3 is a novel target for an immunosuppressive agent, which specifically acts on the immune system (13). In contrast to previous reports, vascular endothelial cells and non-lymphoid and non-myeloid cells can also express and induce significant levels of JAK3 via treatment with interleukin (IL)-1 $\beta$, tumor necrosis factor (TNF)- $\alpha$, interferon (IFN) $-\gamma$, and lipopolysaccharide (LPS) (14). However, the role of JAK3 in endothelial cells and disease-modeled animals has yet to be fully elucidated.

In this study, we investigated the effect of JAK3 inhibition on the TNF- $\alpha$-induced expression of cell adhesion molecules in vascular endothelial cells and evaluated the therapeutic potential of JAK3 for myocardial vascular permeability in endotoxemic mice.

\section{Materials and methods}

Antibodies and other reagents. JANEX-1 and recombinant human TNF- $\alpha$ were purchased from Cayman Chemical (Ann Arbor, MI) and R\&D Systems (Minneapolis, MN), respectively. The antibodies against intercellular adhesion molecule (ICAM)-1 and vascular adhesion molecule (VCAM)-1 were obtained from Santa Cruz Biotechnology (Santa Cruz, CA). The anti-human fractalkine antibody was obtained from Torrey Pines BioLabs (Houston, TX). The antibodies against $\mathrm{NF}-\kappa \mathrm{B}$ p65, phospho-NF- $\kappa \mathrm{B}$ p 65, phospho-I $\kappa \mathrm{B}-\alpha$, I $\mathrm{B}-\alpha$, phospho-STAT3, and STAT3 were obtained from Cell Signaling Technology (Beverly, MA). LPS and other biochemical reagents were purchased from Sigma-Aldrich (St. Louis, MO).

Cell culture. The human umbilical vein endothelial cells (HUVECs) were purchased from Lonza Walkersville (Walkersville, MD) and were cultured in EBM-2 complete media supplemented with $2 \%$ (vol/vol) heat-inactivated fetal bovine serum at $37^{\circ} \mathrm{C}$ in $5 \% \mathrm{CO}_{2}$. The THP-1 cells were purchased from the American Type Culture Collection (Manassas, VA) and maintained in RPMI-1640 medium.

Western blot analysis. HUVECs were pretreated with JANEX-1 $(5,10$ or $25 \mu \mathrm{M})$ for 30 min and then stimulated with TNF- $\alpha$ and JANEX-1 for the indicated time and dose. A western blot analysis was performed, as previously described (15), using primary antibodies against ICAM-1, VCAM-1, fractalkine, phospho-STAT3, STAT3, phospho-NF- $\mathrm{B}$ p65, NF- $\mathrm{B}$ p65, phospho-I $\kappa \mathrm{B}-\alpha$, and $\mathrm{I} \kappa \mathrm{B}-\alpha$. The membranes were then reblotted with an anti-actin antibody to verify equal loading of protein in each lane. All signals were visualized using chemiluminescent reagents (Amersham Pharmacia Biotech, London, UK) and analyzed by densitometric scanning (LAS3000; Fuji Film, Tokyo, Japan).

Cytoplasmic and nuclear protein extraction. The extraction of cytoplasmic and nuclear proteins from HUVECs was performed using a nuclear and cytoplasmic extraction reagents kit (Thermo Scientific, Rockford, IL), according to the manufacturer's protocol. The nuclear extracts $(20 \mu \mathrm{g})$ were immunoblotted with an anti-NF- $\kappa$ B p 65 antibody, and the cytosolic fractions $(20 \mu \mathrm{g})$ were immunoblotted with an anti-IкB- $\alpha$ antibody.

Animal experiments. Fifty male C57BL/6 mice (7 weeks old, weighing 20-23 g) were purchased from Orient Bio Inc. (Charles River Korea, Seoul, Korea) and maintained under a standard laboratory diet with water ad libitum. The animal experimental protocol was reviewed and approved by the Institutional Animal Care and Use Committee of Chonbuk National University. The mice were divided into 4 groups: the control buffer-treated group ( $\mathrm{n}=10)$, the JANEX-1 group $(\mathrm{n}=10)$, the LPS group $(n=15)$ and the LPS plus JANEX-1 group $(n=15)$. JANEX-1 (50 mg/kg), dissolved in $0.1 \%$ dimethylsulfoxide, was administered via a single intraperitoneal injection $1 \mathrm{~h}$ prior to the induction of endotoxemia. Endotoxemia was induced by an intraperitoneal injection of LPS $(15 \mathrm{mg} / \mathrm{kg})$. At 2 or $24 \mathrm{~h}$ after the induction of endotoxemia, the mice were anesthetized with ketamine $(100 \mathrm{mg} / \mathrm{kg})$ and xylazine $(10 \mathrm{mg} / \mathrm{kg})$. Blood was collected by intracardiac puncture, and the heart was harvested for western blot analysis and histological examination.

Immunohistochemical analysis of ICAM-1. Immunohistochemical staining for ICAM-1 was performed as previously described (15). All of the slides were evaluated by two blinded observers using a Zeiss Z1 microscope (Carl Zeiss, Göttingen, Germany). The extent of ICAM-1 immunostaining in the heart tissue was expressed as a percentage of the area of 10 random, non-overlapping fields per slide (magnification $\mathrm{x} 400$ ) using a digital image analysis program (AnalySIS, Soft Imaging System, Münster, Germany).

Vascular permeability measurement using Evans blue dye. The microvascular leakage of Evans blue dye was assessed using a previously described protocol (16). The experimental groups consisted of the control buffer-treated group $(n=5)$, the JANEX-1 group $(n=5)$, the LPS group $(n=10)$ and the LPS plus JANEX-1 group $(n=10)$. Thirty minutes prior to the end of the experiment, the mice were anesthetized with ketamine $(100 \mathrm{mg} / \mathrm{kg})$ and xylazine $(10 \mathrm{mg} / \mathrm{kg})$ and injected with $2 \mathrm{ml}$ of Evans blue dye (1\% in normal saline) per kg body weight through a tail vein. At the time of sacrifice, the mice were perfused with normal saline through the left ventricle. The heart was excised, dried by centrifugation at $25^{\circ} \mathrm{C}$ under vacuum, and weighed to estimate the dry weight. The heart was homogenized in $1 \mathrm{ml}$ of formamide, incubated at $55^{\circ} \mathrm{C}$ for $18 \mathrm{~h}$, and then centrifuged at $16,000 \mathrm{xg}$ for $30 \mathrm{~min}$ at $4^{\circ} \mathrm{C}$. The amount of Evans blue dye in the supernatant was determined by measuring the absorbance at $620 \mathrm{~nm}$ with a SmartSpec Plus spectrophotometer (Bio-Rad, Hercules, CA) and correcting for the extraction volume.

Statistical analysis. Data are expressed as the means \pm SD. Mean comparisons between two groups were examined for significant differences using one-way ANOVA followed by individual comparison with Tukey's post hoc test, with $\mathrm{P}<0.05$ indicating a statistically significant difference. 

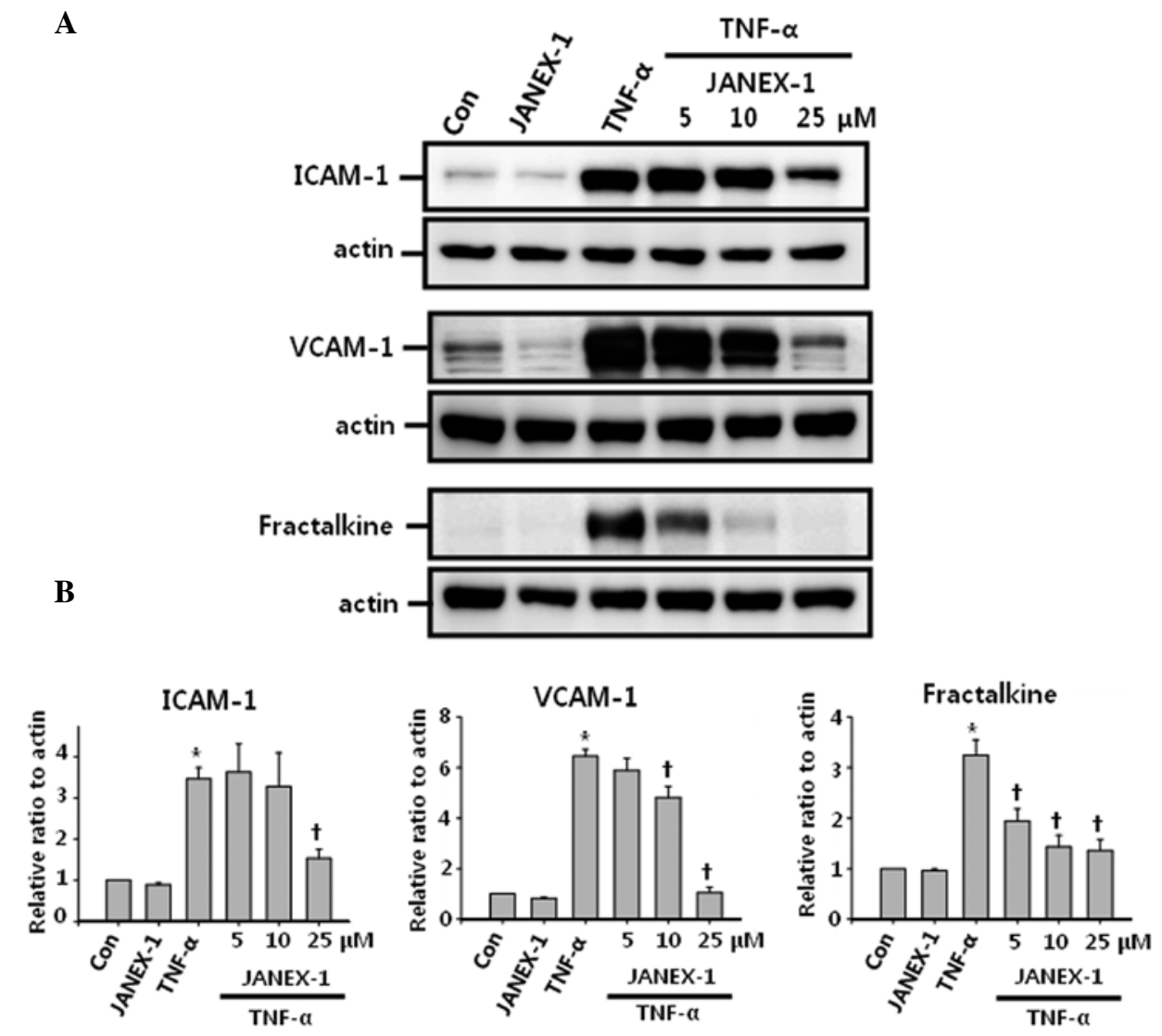

Figure 1. Inhibition of the JAK/STAT pathway by JANEX-1 decreases TNF- $\alpha$-induced cell adhesion molecule expression in HUVECs. (A) Immunoblot analyses of intercellular adhesion molecule (ICAM)-1, vascular cell adhesion molecule (VCAM)-1 and fractalkine expression in TNF- $\alpha$-stimulated HUVECs treated with the JAK3 inhibitor, JANEX-1. The HUVECs were incubated for $6 \mathrm{~h}$ with control buffer (Con), JANEX-1 $(25 \mu \mathrm{M})$, TNF- $\alpha(10 \mathrm{ng} / \mathrm{ml})$, or TNF- $\alpha$ plus JANEX-1 $(5,10,25 \mu \mathrm{M})$. (B) The densitometric analyses are presented as the relative ratios of ICAM-1, VCAM-1 and fractalkine to actin. The ratio relative to Control (Con) is arbitrarily presented as 1 . Bars represent the mean \pm SD of three experiments. " $\mathrm{p}<0.05$ vs. Con, ${ }^{\dagger} \mathrm{p}<0.05$ vs. TNF- $\alpha$ only.

A
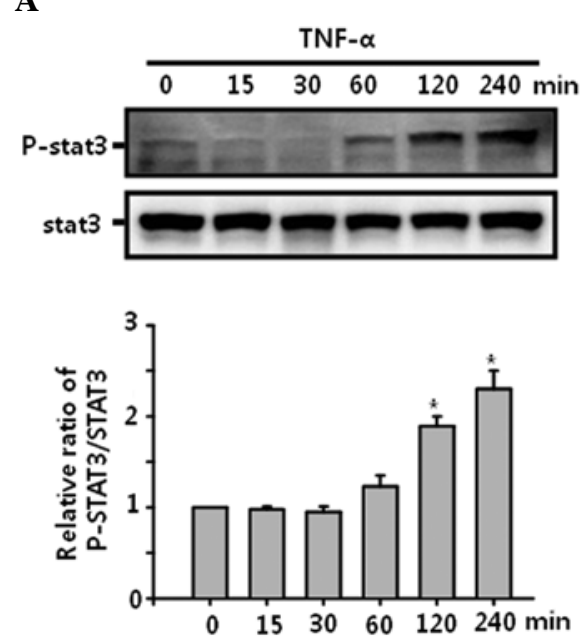
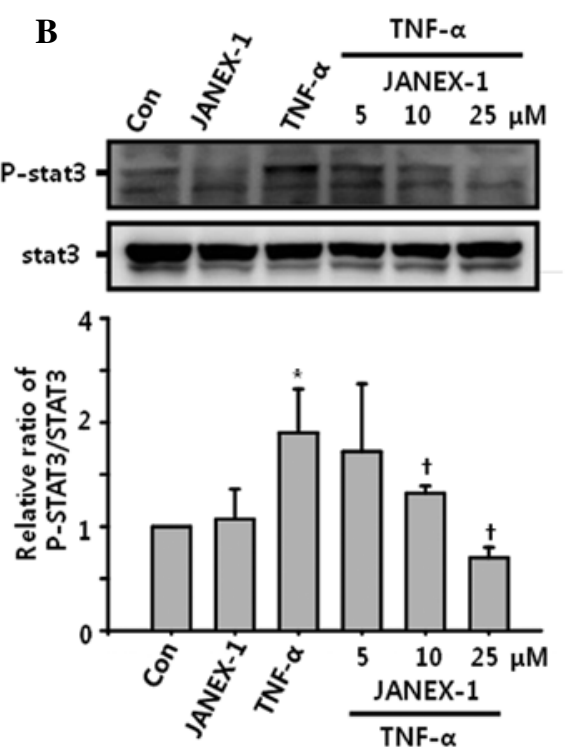

Figure 2. JANEX-1 decreases the TNF- $\alpha$-induced expression of phospho-STAT3 in HUVECs. (A) Immunoblot analyses of the expression of phospho-STAT3 in TNF- $\alpha$-stimulated HUVECs. The HUVECs were incubated for 0, 15, 30, 60, 120 and 240 min with TNF- $\alpha$ (10 ng/ml). TNF- $\alpha$ increased STAT3 phosphorylation at $120 \mathrm{~min}$, and this increase peaked at $240 \mathrm{~min}$. The densitometric analyses are presented as the relative ratio of phospho-STAT3 to STAT3. The ratio relative to Con is arbitrarily presented as 1 . The bars represent the mean \pm SD. of three experiments. "p $<0.05$ vs. the control (Con). (B) Immunoblot analyses of the expression of phospho-STAT3 in TNF- $\alpha$-stimulated HUVECs treated with the JAK3 inhibitor, JANEX-1. The HUVECs were incubated for $4 \mathrm{~h}$ with control buffer (Con), JANEX-1 (25 $\mu \mathrm{M})$, TNF- $\alpha(10 \mathrm{ng} / \mathrm{ml})$, or TNF- $\alpha$ plus JANEX-1 $(5,10,25 \mu \mathrm{M})$. The densitometric analyses are presented as the relative ratio of phospho-STAT3 to STAT3. The ratio relative to Con is arbitrarily presented as 1 . The bars represent the mean \pm SD of three experiments. ${ }^{*}<<0.05$ vs. Con, ${ }^{\dagger} \mathrm{p}<0.05$ vs. TNF- $\alpha$ only. 
A
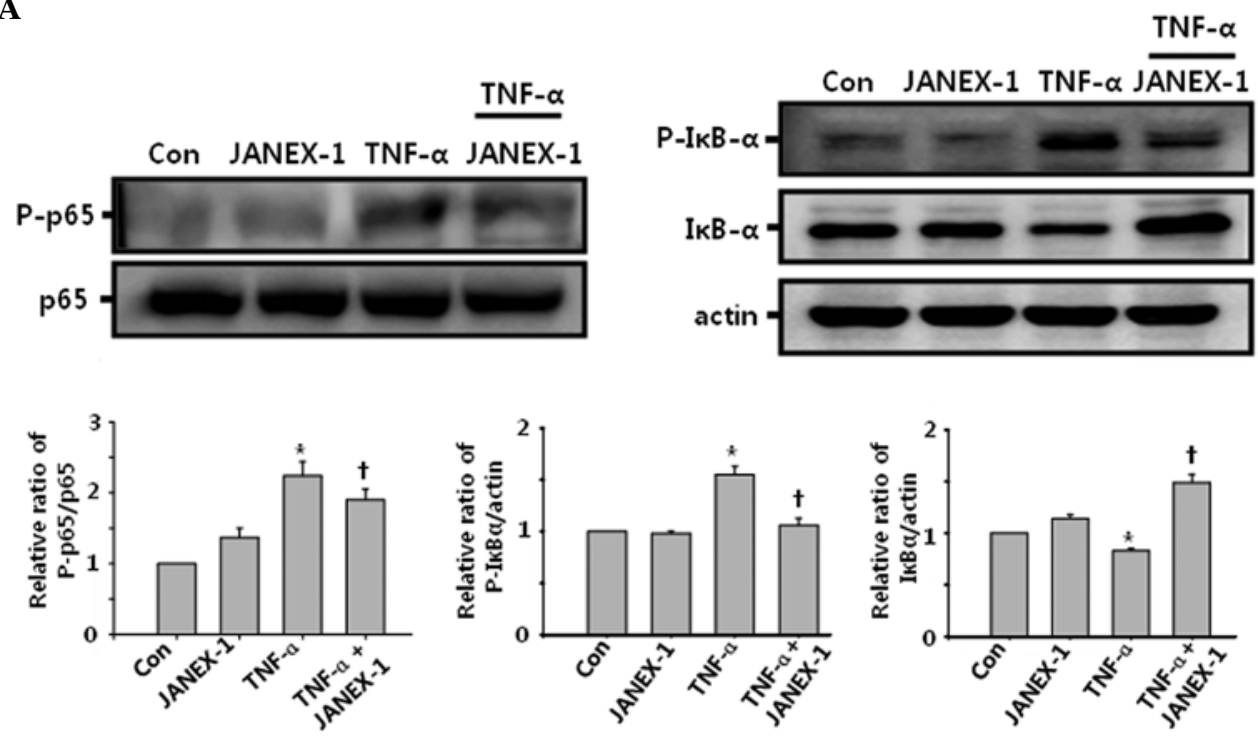

TNF- $\alpha$

B
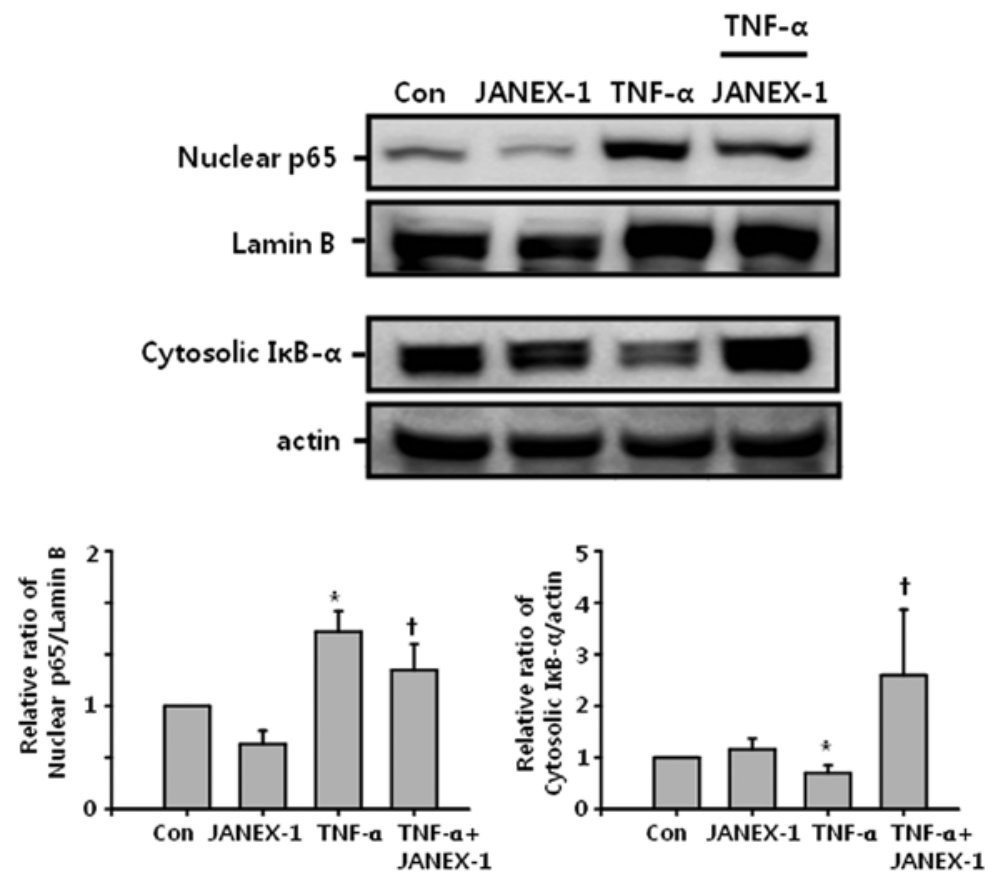

Figure 3. JANEX-1 inhibits TNF- $\alpha$-induced NF-kB activation in endothelial cells. (A) HUVECs were incubated for $4 \mathrm{~h}$ with control buffer (Con), JANEX-1 $(25 \mu \mathrm{M})$, TNF- $\alpha(10 \mathrm{ng} / \mathrm{ml})$, or TNF- $\alpha$ plus JANEX-1 (25 $\mu \mathrm{M})$. JANEX-1 decreased the TNF- $\alpha$-induced increase of phospho-p65 expression in the whole cell lysate of HUVECs. The densitometric analyses are presented as the relative ratio of phospho-p65 to p65. The ratio relative to Con is arbitrarily presented as 1 . The bars represent the mean \pm SD of three experiments. " $p<0.05$ vs. Con, ${ }^{\dagger} p<0.05$ vs. TNF- $\alpha$ only. JANEX-1 decreased the TNF- $\alpha$-induced increase of

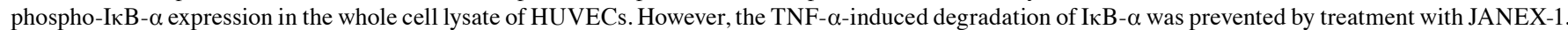

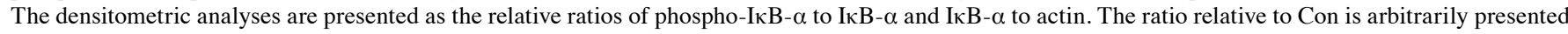
as 1 . The bars represent the mean \pm SD of three experiments. " $p<0.05$ vs. Con ${ }^{\dagger} p<0.05$ vs. TNF- $\alpha$ only. (B) JANEX-1 decreased the TNF- $\alpha$-induced increase of nuclear p65 expression in the nuclear extract of HUVECs. However, the TNF- $\alpha$-induced degradation of cytosolic IкB- $\alpha$ was ameliorated by treatment with JANEX-1. The densitometric analyses are presented as the relative ratios of nuclear p65 to lamin B and cytosolic IкB- $\alpha$ to actin. The ratio relative to Con is arbitrarily presented as 1 . Bars represent the mean $\pm \mathrm{SD}$ of three experiments. ${ }^{*} \mathrm{p}<0.05$ vs. Con ${ }^{\dagger} \mathrm{p}<0.05$ vs. TNF- $\alpha$ only.

\section{Results}

Inhibition of JAK3 reduces TNF- $\alpha$-induced expression of cell adhesion molecule in HUVECs. In this study, we used $10 \mathrm{ng} / \mathrm{ml}$ of TNF- $\alpha$ in accordance with our previous work (17). To investigate the effect of JAK3 inhibition on the TNF- $\alpha$-induced expression of ICAM-1, VCAM-1, and fractalkine, HUVECs were pretreated with JANEX-1 for $30 \mathrm{~min}$ and then incubated with TNF- $\alpha$ for $6 \mathrm{~h}$. Western blot analyses revealed that TNF- $\alpha$ significantly increased the levels of ICAM-1, VCAM-1, and fractalkine proteins relative to the levels observed in the control samples. The pretreatment of HUVECs with a JAK3 inhibitor, JANEX-1, blocked the effect of TNF- $\alpha$ on the expression of ICAM-1, VCAM-1, and fractalkine in a dosedependent manner (Fig. 1). JANEX-1 alone did not alter the expression of the adhesion molecules. 

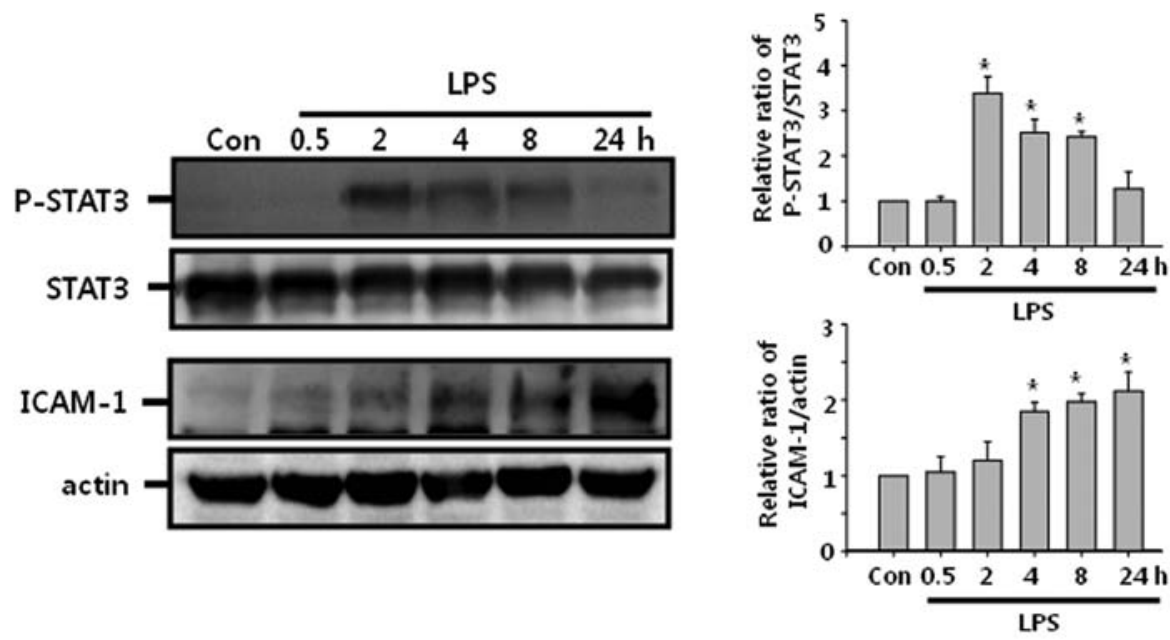

Figure 4. Expression of cardiac phospho-STAT3 and ICAM-1 after the induction of endotoxemia. Immunoblot analyses of phospho-STAT3 and ICAM-1 in the heart. After the induction of endotoxemia, the heart was harvested at $0.5,2,4,8$, or $24 \mathrm{~h}$. The densitometric analyses are presented as the relative ratios of phospho-STAT3 to STAT3 and ICAM-1 to actin. The ratio relative to the control (Con) is arbitrarily presented as 1 . The bars represent the mean \pm SD for three experiments. ${ }^{*} \mathrm{p}<0.05$ vs. Con.

JANEX-1 decreases TNF- $\alpha$-induced phophorylation of STAT3 in HUVECs. To examine whether TNF- $\alpha$ activates STAT3, the degree of phosphorylation of STAT3 was determined by western blotting. The treatment of HUVECs with TNF- $\alpha$ increased STAT3 phosphorylation in a time-dependent manner (Fig. 2A). Because JAK3 is the upstream signaling molecule of STAT3, we also evaluated the effect of JANEX-1 on TNF- $\alpha$-induced STAT3 activation. HUVECs were treated with various concentrations of JANEX-1 for $30 \mathrm{~min}$ and then incubated with TNF- $\alpha$ for 6 h. JANEX-1 blocked the TNF- $\alpha$ induced STAT3 phosphorylation in a dose-dependent manner (Fig. 2B). JANEX-1 alone did not alter the phosphorylation level of STAT3.

JANEX-1 inhibits TNF- $\alpha$-induced $N F-\kappa B$ activation in HUVECs. NF- $\mathrm{\kappa B}$ activates and coordinates the inflammatory cascade in endotoxemia (9). To examine whether JAK3 is involved in this TNF- $\alpha$-induced NF- $\kappa$ B activation, we assessed the TNF- $\alpha$-induced NF- $\kappa$ B p65 phosphorylation by western blotting. Pretreatment of JANEX-1 decreased the TNF- $\alpha$ induced increase of the phospho-p65 level in HUVECs. We also evaluated the TNF- $\alpha$-induced degradation of IкB- $\alpha$ in HUVECs. Treatment with TNF- $\alpha$ significantly increased the phosphorylation and degradation of I $\mathrm{KB}-\alpha$, whereas JANEX-1 attenuated the TNF- $\alpha$-induced increase in the phosphorylation and degradation of IкB- $\alpha$ in HUVECs (Fig. 3A). To verify the effect of JANEX-1 on the TNF- $\alpha$-induced nuclear translocation of NF- $\kappa B$ p65, we assessed the expression of TNF- $\alpha$-induced nuclear p65 and cytosolic IкB- $\alpha$ after JANEX-1 treatment. As expected, the TNF- $\alpha$-induced increase in the nuclear translocation of $\mathrm{p} 65$ was significantly attenuated by pretreatment with JANEX-1, and the TNF- $\alpha$-induced degradation of cytosolic IкB- $\alpha$ was prevented by JANEX-1 (Fig. 3B).

JANEX-1 improves myocardial vascular leakage by decreasing STAT3 phosphorylation and ICAM-1 expression in endotoxemic mice. To verify the above findings from the in vitro study, we performed in vivo experiments using endotoxemic mice that were established by injecting LPS. First, changes in cardiac STAT3 phosphorylation and ICAM-1 expression were evaluated. The injection of LPS into mice increased the levels of phosphorylated STAT3 and ICAM-1 in the heart tissue in a time-dependent manner. The level of phospho-STAT3 was significantly increased at $2 \mathrm{~h}$ after the injection of LPS and decreased at $24 \mathrm{~h}$. The expression of ICAM-1 was increased at $24 \mathrm{~h}$ after the induction of endotoxemia (Fig. 4).

Pretreatment with JANEX-1 effectively decreased the level of phospho-STAT3 at $2 \mathrm{~h}$ after the induction of endotoxemia in the heart tissue. JANEX-1 also significantly decreased ICAM-1 expression at $24 \mathrm{~h}$ after endotoxemia induction (Fig. 5A). In addition, we evaluated the localization of endotoxemia-induced ICAM-1 expression in the heart using immunohistochemical staining. Endotoxemia increased ICAM-1 expression in the arteriolar and capillary endothelial cells in the heart. Pretreatment with JANEX-1 prevented the increase of ICAM-1 expression (Fig. 5B). JANEX-1 alone did not induce ICAM-1 expression in the heart.

As endotoxemia is associated with increased myocardial vascular permeability, we examined the effect of JANEX-1 on the endotoxemia-induced vascular leakage of Evans blue dye (16). Endotoxemia significantly increased the vascular leakage, and this effect was significantly reduced by pretreatment with JANEX-1 (Fig. 5C). These data suggest that JANEX-1 attenuates LPS-induced myocardial vascular leakage.

\section{Discussion}

The expression of endothelial cell adhesion molecules during sepsis is an important step in the inflammatory reaction leading to major organ dysfunction. To prevent and treat sepsis-induced organ dysfunction, clinicians need to apply a multi-disciplinary approach, such as hemodynamic support, airway management, antibiotic therapy and control of inflammation. In the present study, we examined the involvement of JAK3 in the TNF- $\alpha$ induced expression of endothelial cell adhesion molecules and endotoxemia-induced myocardial dysfunction. The results 
A

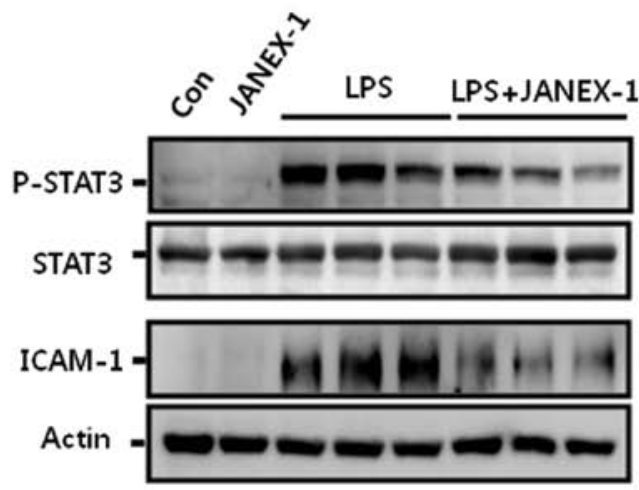

B

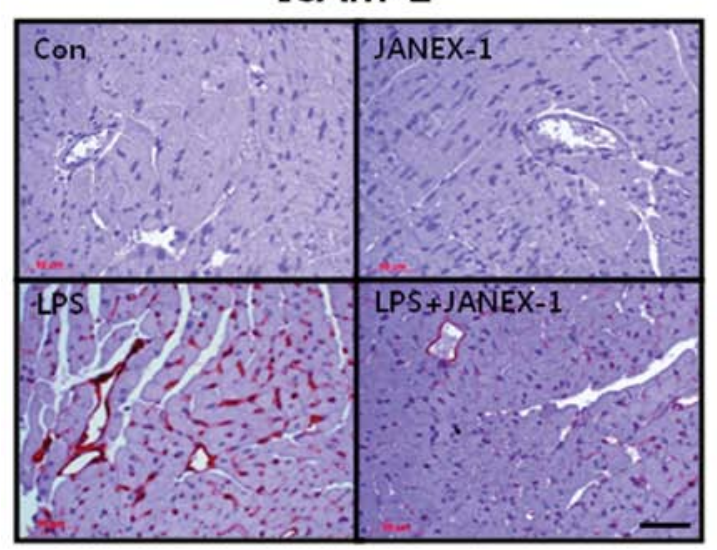

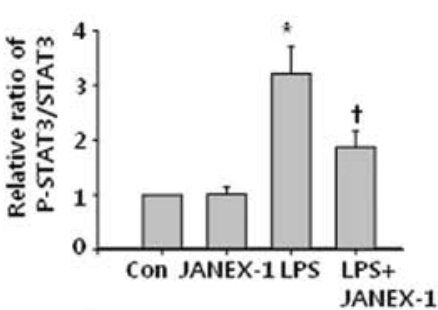

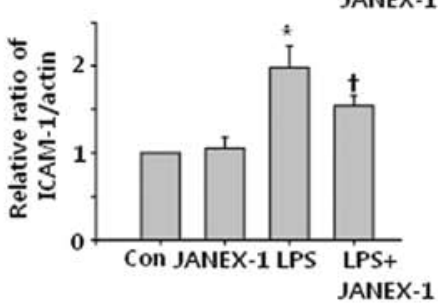

C
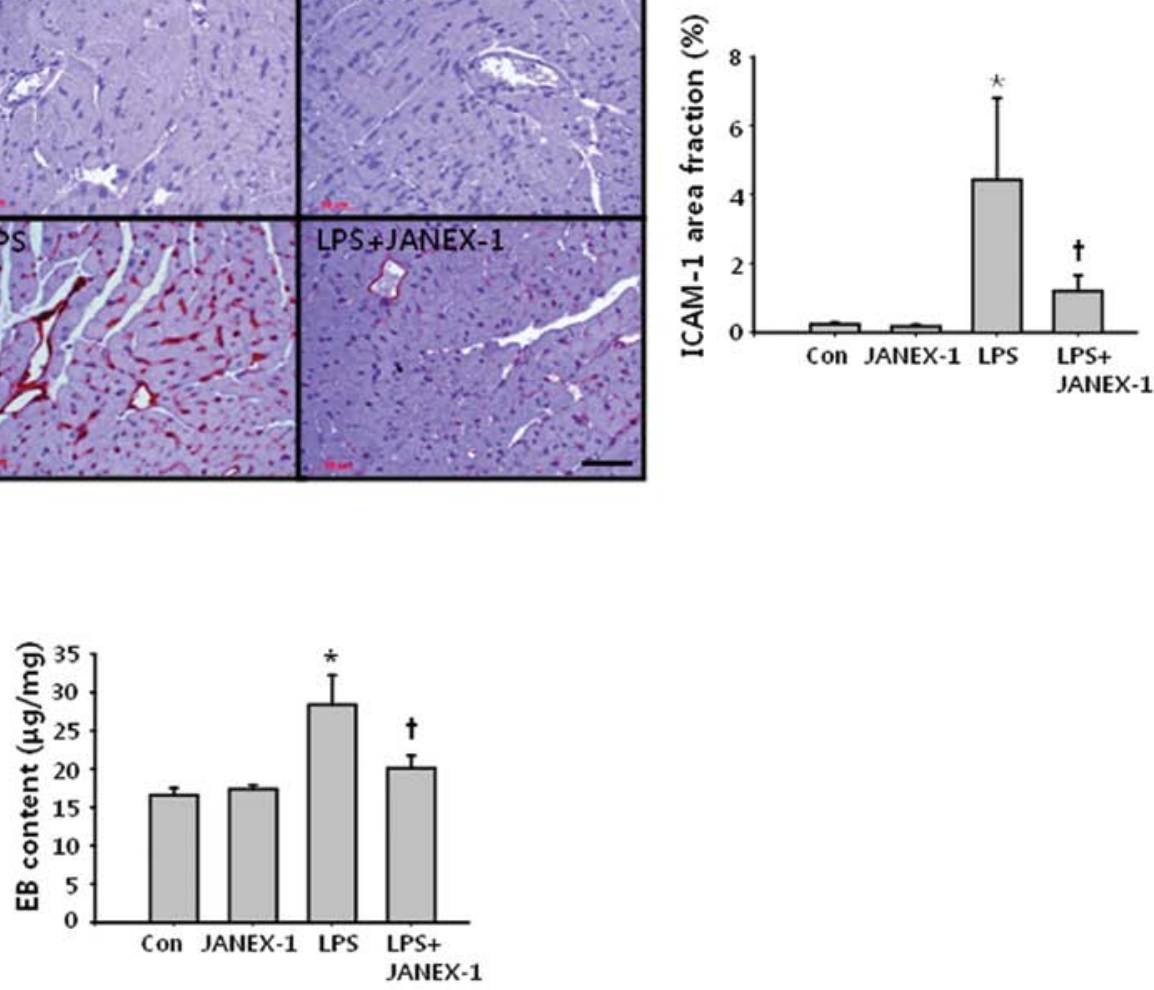

Figure 5. Effects of JANEX-1 on cardiac STAT3 phosphorylation, ICAM-1 expression and vascular permeability in endotoxemic mice. (A) Immunoblot analyses of cardiac phospho-STAT3 and ICAM-1 after pretreatment of endotoxemic mice with JANEX-1. The hearts from the mice treated with the control buffer (Con), JANEX-1, LPS and LPS plus JANEX-1 were harvested 2 or $24 \mathrm{~h}$ after the induction of endotoxemia for STAT3 phosphorylation and ICAM-1 expression, respectively. The densitometric analyses are presented as the relative ratios of phospho-STAT3 to STAT3 and ICAM-1 to actin. The ratio relative to Con is arbitrarily presented as 1 . The bars represent the mean \pm SD of three experiments. ${ }^{*}$ p $<0.05$ vs. Con, ${ }^{\dagger}$ p $<0.05$ vs. LPS. (B) Immunohistochemical study of ICAM-1 in the heart. The hearts from the mice treated with the control buffer (Con), JANEX-1, LPS and LPS plus JANEX-1 were harvested 24 h after the induction of endotoxemia. Scale bar, $50 \mu \mathrm{m}$. The quantitative score of ICAM-1 in the heart is presented ( $\mathrm{n}=15$ in each group). The bar graph shows the area density of the positively stained area relative to the area of the total field $\left(0.22 \mu \mathrm{m}^{2}\right)$. The data are expressed as the mean \pm SD of three experiments. ${ }^{*} \mathrm{p}<0.05$ vs. Con, ${ }^{\dagger} \mathrm{p}<0.05$ vs. LPS. (C) The myocardial vascular permeability was quantified with Evans blue dye, $\mathrm{n}=10$ for each experimental group. The data are expressed as the mean $\pm \mathrm{SD}$ of three experiments. ${ }^{*} \mathrm{p}<0.05$ vs. Con, ${ }^{\dagger} \mathrm{p}<0.05$ vs. LPS.

revealed that treatment with JANEX-1 reduces the TNF- $\alpha$ mediated expression of ICAM-1, VCAM-1, and fractalkine in endothelial cells as well as the adhesion of monocytes to endothelial cells. In endotoxemic mice, the pretreatment of mice with JANEX-1 inhibited not only ICAM-1 expression in heart tissue but also endotoxemia-induced myocardial microvascular leakage and dysfunction.
During endotoxemia, the vascular endothelial cells are affected by the inflammatory cytokines that induce the expression of cell adhesion molecules, such as ICAM-1, VCAM-1, and fractalkine $(9,16)$. Following the expression of cell adhesion molecules, inflammatory cells, such as neutrophil and polymorphonuclear cells migrate into the tissue and are activated at the site of inflammation (18). Endotoxemia-induced endothelial 
dysfunction also alters myocardial function by depression of myocyte contractility and promotes the activation of local inflammatory responses and the generation of reactive oxygen species (19). Therefore, targeting endothelial inflammatory responses, such as the expression of cell adhesion molecules, may be a plausible approach to treating endotoxemia-induced myocardial dysfunction. In the present study, the results demonstrate that the inhibition of JAK3 alleviates the TNF- $\alpha$-induced expression of ICAM-1, VCAM-1, and fractalkine in HUVECs.

$\mathrm{NF}-\kappa \mathrm{B}$ is an essential mediator of septic organ injury, and regulation of the $\mathrm{NF}-\kappa \mathrm{B}$ signal is an important therapeutic target for sepsis-induced vascular dysfunction $(20,21)$. Xu et al have shown that a selective blockade of endothelial NF- $\kappa \mathrm{B}$ signaling in septic mice reduces the expression of tissue ICAM-1 and VCAM-1 and the vascular permeability in the heart, lung, liver, and kidney (18). In addition, Yang et al demonstrated that transcription of ICAM-1 in the vascular endothelium is regulated by the Sp1-STAT3 complex following myocardial ischemia-reperfusion injury (22). Therefore, targeting the $\mathrm{NF}-\kappa \mathrm{B}$ and JAK/STAT signaling pathways may be crucial for maintaining vascular homeostasis during endotoxemia. In the present study, JANEX-1 reduced the TNF- $\alpha$-mediated nuclear translocation of NF- $\kappa \mathrm{B}$ p 65 and the degradation of $\mathrm{I} \kappa \mathrm{B}-\alpha$ in vascular endothelial cells, suggesting that $\mathrm{NF}-\kappa \mathrm{B}$ is in the TNF- $\alpha / J A K 3$ signaling axis. These findings suggest that the JAK/STAT signaling pathway, specifically the JAK3/STAT3 pathway, may play a critical role in regulating the endothelial cell expression of adhesion molecules by TNF- $\alpha$.

Sepsis is characterized by a blunting of the endothelial response and an increase in vascular permeability (4). Sepsisinduced blunting of the endothelial response results in the dysregulation of arteriolar tone and contributes to myocardial dysfunction. In our endotoxemic model, myocardial permeability was significantly increased, whereas the pretreatment of mice with JANEX-1 prevented the induction of cardiac dysfunction by endotoxemia. Moreover, the induction of endotoxemia in mice increased the phosphorylation of STAT3 and the expression of ICAM-1 in the heart tissue. Consistent with these findings, our immunohistochemical study revealed that ICAM-1 expression was increased in the myocardial arteriolar and capillary endothelial cells, and pretreatment with JANEX-1 substantially attenuated the increase of ICAM-1 expression. These observations suggest that the regulation of endothelial responses by inhibiting the JAK/STAT pathway may ameliorate the myocardial vascular leakage caused by endotoxemia.

In conclusion, inhibition of the JAK/STAT pathway by JANEX-1 ameliorates the TNF- $\alpha$-induced cell adhesion molecule expression in endothelial cells and may modulate the vascular inflammatory process in sepsis.

\section{Acknowledgements}

We thank Dr Mie-Jae Im for the critical review of the manuscript and Ki Dong Lee for the excellent technical assistance. This work was supported by the Ministry of Science \& Technology (MoST)/Korea Science \& Engineering Foundation (KOSEF) through the Diabetes Research Center at Chonbuk National University (Grant 2011-0028225, to K.P.K) and by funding from the Chonbuk National University Hospital Research Institute of Clinical Medicine in 2011 (to K.P.K).

\section{References}

1. Levy MM, Fink MP, Marshall JC, Abraham E, Angus D, Cook D, Cohen J, Opal SM, Vincent JL and Ramsay G: 2001 SCCM/ESICM/ACCP/ATS/SIS International Sepsis Definitions Conference. Crit Care Med 31: 1250-1256, 2003.

2. Zhang WJ, Wei H, Hagen T and Frei B: Alpha-lipoic acid attenuates LPS-induced inflammatory responses by activating the phosphoinositide 3-kinase/Akt signaling pathway. Proc Natl Acad Sci USA 104: 4077-4082, 2007.

3. Cines DB, Pollak ES, Buck CA, Loscalzo J, Zimmerman GA, McEver RP, Pober JS, Wiek TM, Konkle BA, Schmidt AM, et al: Endothelial cells in physiology and in the pathophysiology of vascular disorders. Blood 91: 3527-3561, 1998.

4. Aird WC: The role of the endothelium in severe sepsis and multiple organ dysfunction syndrome. Blood 101: 3765-3777, 2003.

5. Bolli R, Dawn B and Xuan YT: Emerging role of the JAK-STAT pathway as a mechanism of protection against ischemia/reperfusion injury. J Mol Cell Cardiol 33: 1893-1896, 2001.

6. Scott MJ, Godshall CJ and Cheadle WG: Jaks, STATs, cytokines, and sepsis. Clin Diagn Lab Immunol 9: 1153-1159, 2002.

7. El-Adawi H, Deng L, Tramontano A, Smith S, Mascareno E, Ganguly K, Castillo R, and El-Sherif N: The functional role of the JAK-STAT pathway in post-infarction remodeling. Cardiovasc Res 57: 129-138, 2003.

8. Boengler K, Hilfiker-Kleiner D, Drexler H, Heusch G and Schulz R: The myocardial JAK/STAT pathway: from protection to failure. Pharmacol Ther 120: 172-185, 2008.

9. Moon SO, Kim W, Sung MJ, Lee S, Kang KP, Kim DH, Lee SY, So JN and Park SK: Resveratrol suppresses tumor necrosis factor-alpha-induced fractalkine expression in endothelial cells. Mol Pharmacol 70: 112-119, 2006.

10. Bollrath J and Greten FR: IKK/NF-kappaB and STAT3 pathways: central signalling hubs in inflammation-mediated tumour promotion and metastasis. EMBO Rep 10: 1314-1319, 2009.

11. Grivennikov SI and Karin M: Dangerous liaisons: STAT3 and NF-kappaB collaboration and crosstalk in cancer. Cytokine Growth Factor Rev 21: 11-19, 2010.

12. Gurniak CB and Berg LJ: Murine JAK3 is preferentially expressed in hematopoietic tissues and lymphocyte precursor cells. Blood 87: 3151-3160, 1996.

13. Changelian PS, Flanagan ME, Ball DJ, Kent CR, Magnuson KS, Martin WH, Rizzuti BJ, Sawyer PS, Perry BD, Brissette WH, et al: Prevention of organ allograft rejection by a specific Janus kinase 3 inhibitor. Science 302: 875-878, 2003.

14. Verbsky JW, Bach EA, Fang YF, Yang L, Randolph DA and Fields LE: Expression of Janus kinase 3 in human endothelial and other non-lymphoid and non-myeloid cells. J Biol Chem 271: 13976-13980, 1996.

15. Kang KP, Kim DH, Jung YJ, Lee AS, Lee S, Lee SY, Jang KY, Sung MJ, Park SK and Kim W: Alpha-lipoic acid attenuates cisplatin-induced acute kidney injury in mice by suppressing renal inflammation. Nephrol Dial Transplant 24: 3012-3020, 2009.

16. Kim DH, Jung YJ, Lee AS, Lee S, Kang KP, Lee TH, Lee SY, Jang KY, Moon WS, Choi KS, et al: COMP-angiopoietin-1 decreases lipopolysaccharide-induced acute kidney injury. Kidney Int 76: 1180-1191, 2009.

17. Sung MJ, Kim W, Ahn SY, Cho CH, Koh GY, Moon SO, Kim DH, Lee S, Kang KP, Jang KY and Park SK: Protective effect of alpha-lipoic acid in lipopolysaccharide-induced endothelial fractalkine expression. Circ Res 97: 880-890, 2005.

18. Xu H, Ye X, Steinberg H and Liu SF: Selective blockade of endothelial NF-kappaB pathway differentially affects systemic inflammation and multiple organ dysfunction and injury in septic mice. J Pathol 220: 490-498, 2010.

19. Price S, Anning PB, Mitchell JA and Evans TW: Myocardial dysfunction in sepsis: mechanisms and therapeutic implications. Eur Heart J 20: 715-724, 1999.

20. Ye X, Ding J, Zhou X, Chen G and Liu SF: Divergent roles of endothelial NF-kappaB in multiple organ injury and bacterial clearance in mouse models of sepsis. J Exp Med 205: 1303-1315, 2008.

21. Ding J, Song D, Ye X and Liu SF: A pivotal role of endothelialspecific NF-kappaB signaling in the pathogenesis of septic shock and septic vascular dysfunction. J Immunol 183: 4031-4038, 2009.

22. Yang XP, Irani K, Mattagajasingh S, Dipaula A, Khanday F, Ozaki M, Fox-Talbot K, Baldwin WM III, and Becker LC: Signal transducer and activator of transcription 3 alpha and specificity protein 1 interact to upregulate intercellular adhesion molecule-1 in ischemic-reperfused myocardium and vascular endothelium. Arterioscler Thromb Vasc Biol 25: 1395-1400, 2005. 